\title{
A Computação sob a Ótica de Meninas do Ensino Médio
}

\author{
Mateus Paludo Santos, Cristina Paludo Santos, Cristiane Ellwanger
}

Universidade Regional Integrada do Alto Uruguai e das Missões (URI)

98.802-470 - Santo Ângelo - RS - Brasil

mateus.paludo14@hotmail.com,paludo@san.uri.br, cristianeellwanger@gmail.com

\begin{abstract}
This paper presents a panorama that reflects a mapping and analysis carried out with high school girls, with the purpose of identifying important aspects to be contemplated in the planning of actions for the democratization of the knowledge and attraction of girls to the area of Computing. The results depict the discrepancies identified in the different spheres outlined in the mapping.

Resumo. Este artigo apresenta um panorama que reflete um mapeamento e análise, realizado junto a meninas do ensino médio, com vistas a identificar aspectos importantes a serem contemplados no planejamento de ações voltadas à democratização do saber e atração de meninas para a área de computação. Os resultados retratam as discrepâncias identificadas nas diferentes esferas delineadas no mapeamento.
\end{abstract}

\section{Introdução}

A participação de meninas na área de tecnologia e ciências da computação se constituiu uma temática no debate acerca da importância do equilíbrio entre os gêneros nessas áreas. Neste sentido, diversas estratégias estão sendo adotadas com a finalidade de democratizar o saber e o acesso de meninas nas áreas científicas e tecnológicas e quebrar estigmas que foram culturalmente estabelecidos.

Vieira et al. (2013) propôs a produção de peças teatrais como estratégia para possibilitar aos participantes compreender os fundamentos da computação de forma clara e divertida. Já França (2015) propôs o uso do modelo penC em um curso de construção de jogos digitais como forma de introduzir conceitos de lógica de programação em iniciantes na área. Além desta, várias outras iniciativas estão sendo promovidas como forma de desenvolver habilidades por meio da lógica de programação, sendo recorrente o uso de ambientes visuais de programação tais como Scratch [Souza et al., 2015][Rodrigues et al., 2015], App Inventor [Garcia et al., 2016] e RoboMind [Schoeffel et al., 2015].

Tais iniciativas, apesar de utilizarem diferentes estratégias, convergem em sua finalidade disseminando o pensamento computacional como forma de atrair as meninas para a área de computação e, a partir disso, inspirar novos talentos. Estas iniciativas demonstram resultados positivos e negativos em seus desenvolvimentos e tais resultados são importantes para que as ações possam ser otimizadas e replicadas em outras regiões do país.

No entanto, a elaboração de novas estratégias ou a replicação de iniciativas bem sucedidas perpassa pelo entendimento da realidade do público-alvo para o qual a estratégia será aplicada. Neste contexto, insere-se este trabalho que tem como intuito realizar um levantamento de dados 
com vistas a mapear o interesse e conhecimento de meninas, do município de abrangência deste trabalho, no que se refere à área de computação e, a partir disso, definir estratégias com vistas a contribuir para que ocorram mudanças no cenário atual. A metodologia adotada para este mapeamento, bem como os resultados obtidos são apresentados nas seções subsequentes.

\section{Procedimentos Metodológicos}

Para adquirir informações sobre os diferentes matizes de meninas do ensino médio em relação à área de computação elaborou-se um questionário composto por 31 questões divididas, conceitualmente, em quatro (4) principais esferas:

(1) Mapeamento do perfil do público-alvo

(2) Comportamento em relação ao uso da tecnologia;

(3) Conhecimento em relação a área de computação e,

(4) Interesse do público em relação a cursos relacionados com a área de computação.

$\mathrm{Na}$ esfera 1 foram consideradas questões relacionadas à idade das meninas, ano escolar que está sendo cursado, se estuda em rede pública ou privada, se já decidiu em que carreira seguirá os estudos, qual a área de sua preferência e a renda salarial média da família. Já, na esfera 2 as questões envolvem identificar se há o costume do uso de tecnologias no desenvolvimento de trabalhos escolares, com que frequência tais recursos são utilizados, que tipo de recursos mais utiliza e se possui computador em casa.

Para a esfera 3 foram definidas 14 questões que envolvem, por exemplo: "Você sabe o faz um profissional de computação e quais as funções que podem desempenhar?"; "Você sabe como funciona um programa de computador?"; "Um curso de computação só ensina a usar softwares?"; "Trabalhar em computação permite que você exerça sua criatividade?"; dentre outras.

$\mathrm{Na}$ esfera 4 as questões estão relacionadas com o interesse do público-alvo pela área incluindo questões como: "Você pensa em seguir carreira na área de computação?”; "Você gostaria de ser criadora de um aplicativo que auxiliaria diversas pessoas?"; "Você já realizou algum curso relacionado com a área de computação?"; "Você gostaria de participar de cursos para aprender mais sobre a área de computação?"; dentre outras.

O questionário foi aprovado pelo Comitê de Ética em Pesquisas com Seres Humanos da instituição executora sob o número 032-04/PPH-09, obtendo-se o termo de consentimento livre e esclarecido. A aplicação foi realizada em 5 escolas do município. A resposta aos questionários ocorreu de forma anônima e voluntária.

\section{Resultados Obtidos}

Nesta seção são apresentados os resultados significativos das análises gráficas provenientes de questionários respondidos por 198 meninas, sendo: 24\% do primeiro ano, 36\% do segundo ano e $40 \%$ do último ano do ensino médio (esfera 1). Das meninas participantes da pesquisa, 53\% estudam em escolas públicas e $47 \%$ em escolas privadas; $48 \%$ já decidiram em que carreira seguirão seus estudos, enquanto $52 \%$ estão em dúvida ou ainda não decidiram. Quanto a área de preferência, 40\% indicaram Humanas, 32\% Exatas e 28\% Biológicas. A renda salarial média das famílias é de R $\$ 2.800,00$ em $45 \%$ dos casos.

Quanto ao uso de tecnologias (esfera 2), 82\% afirmam usar frequentemente recursos tecnológicos para o desenvolvimento de trabalhos escolares e $18 \%$ só utilizam quando o 
professor solicita. Os recursos mais utilizados são Internet, editores de texto, editores de imagens, redes sociais e e-mail. Recursos como programação e robótica foram citados por apenas 13\% das meninas. Todas as participantes indicam que usam tecnologias diariamente; 79\% possuem computador em casa.

Com relação a esfera 3,12\% indicam saber quais as competências e funções que um profissional de computação pode exercer, $88 \%$ têm apenas uma noção ou não sabem; $68 \%$ percebem que a área é promissora com ampla demanda por profissionais e com várias possibilidades de atuação; $20 \%$ veem a computação como uma área difícil que envolve muita matemática e $12 \%$ relacionam a área com o público masculino. Para as demais questões relacionadas a esta esfera, obteve-se os seguintes resultados: 5\% acreditam que um curso de computação somente ensina a utilizar software, $25 \%$ não sabem o que é ensinado e $70 \%$ não vinculam um curso de computação apenas a utilização de softwares; $52 \%$ acreditam ser necessário saber utilizar o computador para fazer um curso superior na área de computação; $48 \%$ acreditam que não ser necessário ou não sabem; $60 \%$ acham que é difícil a inserção de profissionais da área no mercado de trabalho; $87 \%$ indicam que trabalhar em computação permite que exercer a criatividade; $41 \%$ acreditam que quem trabalha em computação recebe bons salário, entretanto, $51 \%$ não sabem qual a faixa salarial para a profissão.

Quanto ao interesse do público-alvo em relação à área (esfera 4) obteve-se os seguintes resultados: 69\% não pensam em seguir carreira na área de computação, enquanto $31 \%$ cogita ou pensa em seguir carreira na área; 66\% gostariam de desenvolver aplicativos, desde que hajam incentivos para a aprendizagem (cursos); 62\% gostariam de participar de cursos para aprender mais sobre computação; $75 \%$ nunca realizaram cursos.

\section{Discussões e Direcionamentos}

A partir dos resultados obtidos e do estabelecimento de correlações entre as diferentes esferas é possível fazer inferências que podem servir como ponto de partida para a articulação de um plano de ações que conduza a intervenções na realidade atual. A Tabela 1 apresenta algumas inferências realizadas.

Tabela 1. Correlações entre esferas e inferências

Correlações entre as esferas
Esferas 1 e 2: $52 \%$ estão em dúvida ou ainda não
decidiram a carreira a seguir; $13 \%$ citaram o uso
de programação e robótica na confecção de
trabalhos escolares.

Esferas 1 e 3: $88 \%$ das meninas tem apenas uma noção ou não sabem quais as competências de um profissional da computação; $32 \%$ têm preferência pela área das exatas; $52 \%$ estão em dúvida ou não decidiram que carreira irão seguir

Esferas 1 e 4: Renda salarial média da família de $\mathrm{R} \$ 2.800,00$ em $45 \%$ dos casos; $75 \%$ nunca realizaram nenhum curso na área; $62 \%$ gostariam de participar de cursos

\section{Inferências}

- Meninas que tem interesse em programação e robótica podem ser motivadoras das meninas que ainda estão em dúvida ou ainda não optaram pela carreira.

- Falta explanações mais claras sobre a área

- Muitas meninas que têm preferências pela área de Exatas podem estar em dúvida sobre a carreira a seguir. Se tais meninas receberem informações de forma que compreendam melhor a área poderão decidir-se pela computação.

- A renda familiar pode ter influenciado pelo alto percentual de meninas que nunca realizaram nenhum curso na área.

- Apesar de não optarem por seguir carreira na área, têm o interesse na qualificação por meio de cursos para aprender mais sobre a área. 


Esferas 3 e 4: 87\% indicam que trabalhar em
computação permite que exercer a criatividade;
$70 \%$ acreditam que a área da computação vai
além da simples utilização de software; 66\%
gostariam de desenvolver aplicativos; $75 \%$ nunca
aplicativos como forma de expressar a criatividade e
dealizaram cursos
carecem de cursos.

Ao se considerar as particularidades do contexto local pode-se elencar diferentes planos de ação que auxiliem na escolha de estratégias. Neste sentido sugere-se que sejam considerados aspectos como:

- Factibilidade (Diante do mapeamento realizado que alternativas podem intervir na situação identificada? É possível realizar? Há coerência entre a dimensão do problema e a dimensão do plano de ação?);

- Interesse (A ação proposta desperta o interesse? Mobiliza afetivamente? Realmente há interesse em ver a situação modificada?);

- Novidade (A proposta é nova, no sentido de ser um novo momento, um novo grupo? Traz novas perspectivas, novas estratégias? Gera novas ideias e produz mobilizações locais?);

- Ética (A iniciativa é ética? O plano de ação leva em conta os valores e princípios da realidade local?) e,

- Relevância (o problema é relevante? Significativo? Sua solução gerará muitas aprendizagens? Melhorará uma dada realidade?).

\section{Considerações Finais}

Este trabalho teve como objetivo traçar um panorama que retratasse a computação sob a ótica de meninas do ensino médio. O mapeamento realizado apresenta-se como uma estratégia eficaz para auxiliar a visibilidade da área e para articular soluções que impulsionem ações transformadoras.

Embora tenha ocorrido dificuldades na operacionalização do questionário dado a falta de abertura e o tempo de retorno das escolas, obteve-se um número expressivo de participantes, o que proporcionou a realização das inferências e demais desdobramentos delineados nesta pesquisa.

Além das correlações apresentadas, outras induzem a novos questionamentos abrindo espaço para a condução de novas pesquisas com vistas a ampliar a compreensão da situação atual e a articulação de ações. Cabe destacar que os dados obtidos e análises servem de subsídio para o desenvolvimento de um plano de ações a ser executado como próxima etapa do projeto. A confirmação ou refutação das inferências apresentadas neste estudo carecem da realização e avaliação das atividades traçadas no plano de ação. 


\section{Referências Bibliográficas}

França, Rozelma. and Tedesco, Patrícia. "Desafios e oportunidades ao ensino do pensamento computacional na educação básica no Brasil." Anais dos Workshops do Congresso Brasileiro de Informática na Educação. Vol. 4. No. 1. 2015.

Garcia, Victor Ronchi, et al. "Despertando Jovens Talentos com o Conhecimento da Computação." Anais do Workshop de Informática na Escola. Vol. 22. No. 1. 2016.

Rodriguez, C. et al. (2015). Pensamento computacional: transformando ideias em jogos digitais usando o Scratch. In: Anais do Workshop em Informática na Educação. Sociedade Brasileira de Computação, 2015.

Schoeffel, Pablo, et al. "Uma Experiência no Ensino de Pensamento Computacional para Alunos do Ensino Fundamental." Anais dos Workshops do Congresso Brasileiro de Informática na Educação. Vol. 4. No. 1. 2015.

Souza, Suenny Mascarenhas, et al. "Oficinas de Programação com Ambientes Lúdicos para Meninas do Ensino Fundamental." (2015).

Vieira, A., Passos, O. and Barreto, R. Um Relato de Experiência do Uso da Técnica Computação Desplugada. In: Anais do XXI Workshop sobre Educação em Computação. SBC, 2013. p. 670-679. 